\title{
Research on Microgrid and its Application in China
}

\author{
Xing Wu, Xiaogang Yin, Quan Wei, Yifan Jia, Jing Wang \\ Research and Development Center, Xi'an High Voltage Apparatus Research Institute Co., Ltd, Xi'an, China \\ Email: wuxing@xihari.com, yinxiaog@xihari.com, weiquan@xihari.com, jiayifan@xihari.com,wangjing@xihari.com
}

Received February, 2013

\begin{abstract}
This paper presents the state of the art research and application of microgrid in China, and then introduces the major concerns for the development of microgrid. The research related to microgrid in China arose around 2004, focused on the connection of distributed energy resources (DERs) to grid and its influence on distribution network, and then followed the microgrid concept of Consortium for Electric Reliability Technology Solutions (CERTS). However, the microgrid in China has taken a more active path with the development of DER and the encouragement of the development of smart grid and resource and energy needing. Now, nearly every province in China has typical researches and applications of microgrid. Besides, there are already two major patterns in the development of microgrid, the institute-dominating research and the enterprise-dominating application. Research institutions like Tianjin University, Hefei University of Technology, Xi'an Jiaotong University, Institute of Electrical Engineering (Chinese Academy of Sciences), etc., are leading the research on microgrid. The companies like State Grid Corporation of China (SGCC), China Southern Power Grid (CSPG), etc., have accomplished several demonstration projects of microgrid, and give a further boost to its application. At the end of the paper, according to the present situation of the development of microgrid in China, the facing problems and the way to deal with it are put forward.
\end{abstract}

Keywords: Microgrid; Distributed Energy Resources; Research; Demonstration

\section{Introduction}

Since the entrance of 21st century, developing clean energy and ensuring the safety of energy have become the keywords in the energy industry. It is a common goal to build cleaner and more reliable power systems. In order to overcome the negative impact of distributed energy resources (DERs) on power system, and maximize the potential of DERs, the microgrid concept was proposed by Lassster et al at the University of Wisconsin-Madison (UWM). The microgrid can be operated as a single system with DERs and loads [1-3]. The Consortium for Electric Reliability Technology Solutions (CERTS) then presented the white paper on integration of DERs. The CERTS microgrid concept assumes an aggregation of loads and DERs operating as a single system providing both power and heat [4]. The proof of the concept was accomplished at UWM [5], the microgrid test bed was then constructed at Dolan Technology Centre [6].

Typical CERTS microgrid is illustrated in Figure 1 [4]. It consists of micro sources, power and voltage controller, point of common coupling (PCC), circuit breaker, separation device and so on. The CERTS microgrid concept is the most popular microgrid concept around the world. The CERTS microgrid concept is an important reference for the researches and the applications in China.

\section{Background of Microgrid in China}

In China, the microgrid develops with the boom of DER technology, especially the new energy (renewable energy) technology. The Chinese government attaches great importance to the development of distributed energy generation based on new energy. It is clearly stated that China will promote the low-cost large-scale development and utilization of renewable energy in the National Outline for Medium and Long Term Science \& Technology

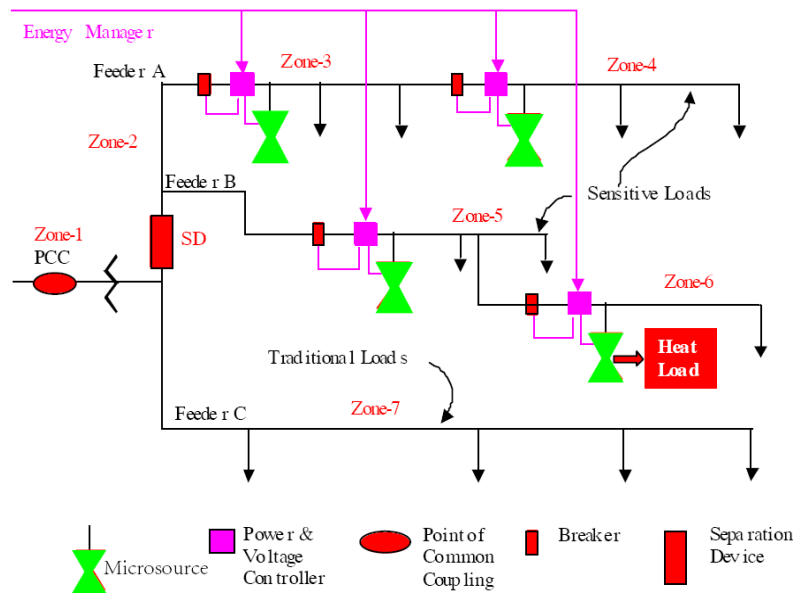

Figure 1. CERTS microgrid architecture. 
Development (2006-2020). The National Outline for 12th Five-Year Science and Technology Development also put forwards a vision for the development of the new energy technology. The latest released Special Planning of 12th Five-Year Plan on Smart Grid Major Science \& Technology Industrialization Projects emphasizes the importance to break through the technology of largescale intermittent new energy and its storage. Chinese government issued Renewable Energy Law of the People's Republic of China, and medium \& long-term Renewable Energy Development Plan to further accelerate the development of DER. With the support of the national policies mentioned above, the amount of investment in renewable energy in China has reached \$51billion in 2011, the total installed capacity of wind power has exceeded $62 \mathrm{GW}$, and newly installed capacity of solar power has increased to $2.2 \mathrm{GW}$. The development of DER technology based on renewable energy in China has been an inevitable trend.

Meanwhile, the research and application of micro-grid in China also continues to heat up. The microgrid in China started by following others, however, it takes a more active way with the support of national policies on DER. Within less than one decade, there are already two developing patterns of microgrid in China, the institute-dominating research and enterprise-dominating application. With financial support of National Basic Research Program (973 Program), National High Technology Development Program (863 Program), National Natural Science Foundation of China (NSFC), etc., the research of microgrid in China includes various aspects of the microgrid technology. At the same time, the state-owned enterprises and the private enterprises increase their investment in the application of DER and microgrid, and nearly every province in China has already had typical DER and microgrid applications.

\section{Research on Microgrid}

The research of microgrid in China began around 2004. It is carried out in accordance with the CERTS microgrid concept, focusing on DERs interconnecting with the bulk power system and their influence on the power network. Now, the research in China covered the key technical issues of microgrid, including: (1) the planning and design of microgrid (including DER)[7-12]; (2)operating characteristics of micro sources [13-15]; (3) microgrid operation and its energy management (including energy storage technology)[16-19]; (4) interconnection of microgrid to the bulk power system[20-22]; (5)island mode of microgrid [23-25]; (6) protection of microgrid [26-28], and so on.

Research institutions like Tianjin University, Hefei University of Technology, Xi'an Jiaotong University, Institute of Electrical Engineering (Chinese Academy of
Sciences), etc., are leading the research on microgrid.

Scholars in Tianjin University started their research from the perspective of planning and design of power system. With the financial support of 973 Program and 863 Program, they carried out research on the planning and design of the microgrid and DERs, the operation, control and protection of the microgrid and the distribution network with DERs. They have built a small microgrid experimental system and an integrated microgrid system [29]. The small microgrid experimental system is illustrated in Figure 2. This is single-phase $230 \mathrm{~V}, 50 \mathrm{~Hz}$ system. It is composed of energy storage system, photovoltaic (PV) simulator, wind power simulator and related control systems. The microgrid central controller (MCC) is used for the energy management. The system can be operated at two steady-state operation modes (interconnection and island), and two transient-state operation modes (transition between interconnection mode and island mode).

Hefei University of Technology developed a microgrid system with multi-energy generators through collaborative research with the University of New Brunswick, Canada [30, 31]. They carried out research on the optimization of the design, control and scheduling strategies of the microgrid. The microgrid structure is shown Figure 3 . The system consists of a $10 \mathrm{~kW}$ single-phase and a $30 \mathrm{kVA}$ three-phase PV generators, two $30 \mathrm{~kW}$ threephase wind generation simulators, $5 \mathrm{~kW}$ fuel cell, $300 \mathrm{Ah}$ battery bank, 1800F ultra-capacitor bank and two sets of $15 \mathrm{~kW}$ conventional generators used to simulate the small hydro and small fossil generators, various loads (resistors, capacitor, inductors, AC and DC motors and other electronic loads). This microgrid has two-layer hierarchical control system, the local controllers and the central controller. An energy management system that conforms to the IEC61970 standards was developed.

The research on microgrid in Xi'an Jiaotong University started with the application of power electronics technology. With the financial support of 863 program and

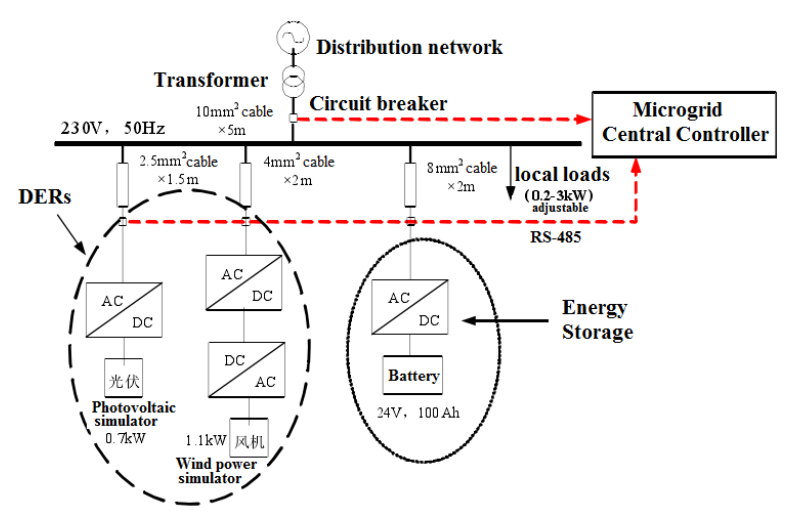

Figure 2. The small microgrid experimental system in Tianjin University. 


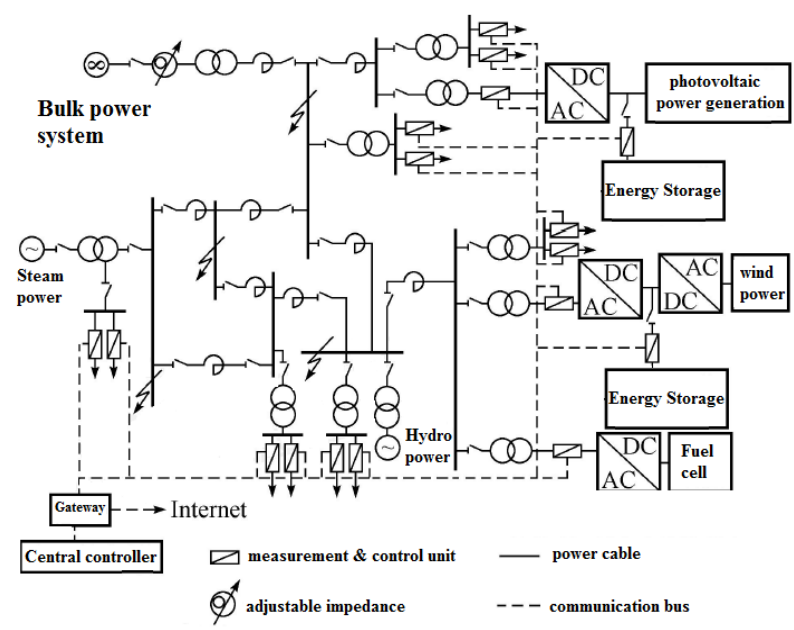

Figure 3. The microgrid system in Hefei University of Technology.

NSFC, they have done extensive and intensive research on the circuit topology and control strategy of power electronics devices in the microgrid, and have developed a fast simulation platform for microgrid based on PSCAD. During this process, they proposed a seamless control strategy to evaluate the platform [32], developed a dynamic reactive power compensation device and its control method for microgrid [33], and proposed a method to use virtual impedance to improve the stability of wireless connection between multiple inverters in microgrid [34]. They also studied the topology of microgrid. The microgrid that they proposed consists of wind, solar, gasoline generators, and energy storage, including battery and super capacitor.

Institute of Electrical Engineering, Chinese Academy of Sciences (IEECAS) is a pioneer of the research on microgrid in China. With the financial support of 863 Program and NSFC, they have done intensive research on the basic theory, key technologies, and experimental platform of microgrid. They also developed a series of control and protection technologies and devices, including a common interface for interconnection between DER and microgrid [35], a hybrid energy storage controller of super capacitor and battery [36], a small-signal model of super capacitor energy storage to improve voltage stability [37], microgrid operation control strategies [17] and so on. Moreover, they built a microgrid test platform, completed the design and commissioning of the grid-connected inverter and other accessories unit, and accomplished combine heat and power (CHP) system in their laboratory. Meanwhile, they built several test platforms for analysis and testing of super capacitor, simulation of dynamic voltage, and AC-DC-AC motor drive system, etc. In addition, the institute has built a number of renewable-energy-generation technology lab, including variable speed constant frequency wind turbine con- verter laboratory stand-alone PV, wind and solar control laboratory, large-scale wind turbine control system laboratory, large-scale grid-connected PV inverter laboratory, power electronics laboratory, and solar thermal power generation test bed.

\section{Application of Microgrid}

Smart grid is the key word in the power industry of China. The implementation of smart grid requires multilevel, robust and reliable electricity network. Microgrid is an important part of the network. Typical Chinese enterprises, like SGCC and CSPG, have done a lot of work to apply the technology of microgrid, and have built several demonstration projects of microgrid with worldleading level.

SGCC is the largest electric utilities company that transmits and distributes power in China and in the world. It proposed the slogan to build a strong smart grid in 2009, and wished to complete the grid in 2020. With the inspiration of this slogan, SGCC has completed many demonstration projects of microgrid and DER, including the pilot project for distributed PV power generation and microgrid operation control in Henan province, the pilot projects for control of microgrid in Hangzhou city and Xi'an city, and the microgrid projects in the rural area of north China.

Zhongxin Tianjin Eco-city microgrid system is the first microgrid system in the constructions for smart grid of SGCC. It realized the communication between microgrid systems and distribution automation system, and data exchange between microgrid and intelligent buildings for the first time. The microgrid system includes a 380V/30kW PV system, $5 \mathrm{~kW}$ wind power, $25 \mathrm{~kW} \times 2 \mathrm{~h}$ energy storage, and monitoring and protection devices. It can achieve autonomous control protection and management, and can be operated at interconnection mode and island mode.

With the support of 863 Program, SGCC led the research on development of key technologies in microgrid with DERs, and developed an integrated platform for control/protection of microgrid. They built an off-grid microgrid demonstration project in Nanlu Island and a grid-connected microgrid demonstration project in Luxi Island. The microgrid in Nanlu Island consists of $10 \times$ $100-\mathrm{kW}$ wind turbines, $545 \mathrm{~kW}$ PV power generation system, $1600 \mathrm{~kW}$ diesel power generation system, $20 \mathrm{~kW}$ ocean current power generation systems, and energy storage system, with integration of electrical vehicle charging station, smart meters and other advanced smartgrid technologies. Luxi Island microgrid is composed of $2 \times 780 \mathrm{~kW}$ wind turbines, $300 \mathrm{~kW}$ PV power generation systems and energy storage system. It can achieve flexible transition between grid-connected mode and off-grid mode. 
To resolve the key issues in the large-scale application of DERs, Zhangbei wind/solar/battery demonstration project is built by SGCC. It is a key project of National Science and Technology Support Program and the National "Golden Sun" Program, and is the first pilot project of SGCC for the strong smart grid. The total investment of this project exceeds $¥ 12$ billion. The entire project contains $500 \mathrm{MW}$ wind power, $100 \mathrm{MW}$ PV and $110 \mathrm{MW}$ batteries, and a $220 \mathrm{kV}$ intelligent substation. The project is an aggregation of all the advanced technologies in power design, wind power, PV, energy storage, control and protection. The first stage of this project had been completed by the end of 2011. The investment of this stage is $¥ 3.3$ billion, including $100 \mathrm{MW}$ wind power, $40 \mathrm{MW}$ PV and 20MW battery. The framework of the system is shown in Figure 4. The wind turbines in this project include the doubly-fed wind turbines, direct-drive wind turbines and the vertical-axis wind turbines. The PV cells include the monocrystalline silicon cell, the polycrystalline silicon cell, amorphous thin-film solar cell and dye-sensitized solar cell. The solar trackers include the fixed tracker, horizontal single-axis tracker, tilted single axis tracker and dual-axis tracker. The batteries contain lithium iron phosphate batteries, vanadium redox batteries and sodium-sulphur batteries. The project will become the world's largest demonstration project with the highest level of intelligent operation of wind power, PV, energy storage.

CSPG pursues the goal to build an intelligent, efficient, reliable and green smart grid. They keep improving the stability and reliability of power system, the utilization efficiency of resources. They have made great efforts to investigate the DER and microgrid technology.

CSPG built a typical microgrid system with combined cooling, heating and power (CCHP) in Foshan city, Guangdong province, providing electricity and cooling for three office buildings. This project belongs to the 863 Program "Study on integration and demonstration of distributed CCHP technology with MW- class gas turbine” and "Study on key technology and demonstration of interconnection of microgrid with MW-class distributed CCHP system”. It focuses on the optimization of design, operation of microgrid, and the impact on the distribution network. The demonstration project started operating in February, 2010. The structure is shown in Figure 5 [38]. The experiment building, part of the loads in dispatch building, and the miroturbines were connected with the low voltage bus LM1, the rest of the loads in dispatch building were connected to LM2. Bus LM3 will provide electricity for the loads in multifunctional building. The CCHP system consists of the microturbine set (three 200kW microturbines) and LiBr double-effect absorption chiller. This project studies protection, control and supervision of power quality in microgrid system with

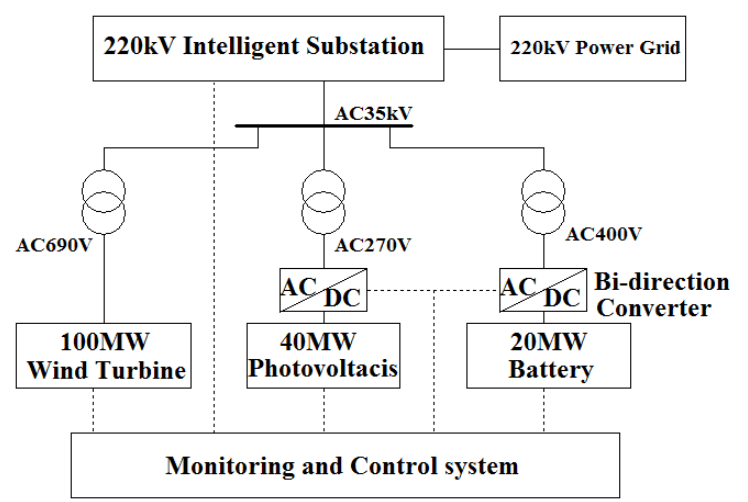

Figure 4. The framework of Zhangbei wind/solar/battery demonstration project.

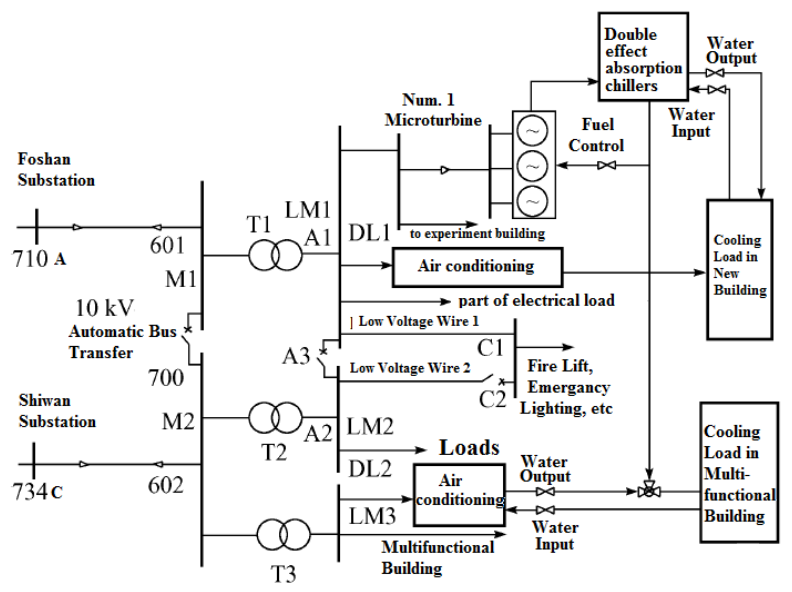

Figure 5. CSPG microgrid system in Foshan city.

CCHP, provides the foundation for the application of DER.

CSPG paid special attention to the energy storage technology. Baoqing, the MW-class energy-storage power station was built in Shenzhen, and came into service in September, 2011. The power station can output $110 \mathrm{kV}$ electricity for industry, the total energy-storage capacity exceeds 12 MWh. Compare with Zhangbei demonstration project focusing on the combination of new energy and energy storage, Baoqing power station pays much attention to load shifting, regulation of voltage/frequency, and microgrid islanding.

\section{Microgrid at Xi'an High Voltage Apparatus Research Institute Co., Ltd}

Xi'an High Voltage Apparatus Research Institute Co., Ltd (XIHARI) has the National Engineering Laboratory for High Voltage Electric, National Energy Research and Development (Testing) Centre for Power Transmission and Distribution Equipment, and National Quality Supervision \& Inspection Test Centre for high voltage apparatus, insulator and surge Arrestor, power capacitor, 
and intelligent power equipment. It is responsible for the research and development of power equipment, power test and establishment of national standards. XIHARI plays a very important role in smart grid, new energy (renewable energy). Microgrid technology is another key technology that XIHARI is developing. Figure 6 shows the framework of on-going microgrid project in XIHARI. This project focuses on economic operation and energy management optimization of microgrid. The microgrid consists of $20 \mathrm{~kW}$ PV, $2 \mathrm{~kW}$ wind power, $20 \mathrm{kWh}$ battery, and diesel generator. Several interfaces are prepared for electrical vehicle charging system and static var generator (SVG).

\section{Prospects of the Microgrid Technology}

As an optimized integration of DER, microgrid has been the focus around the world. Microgrid plays an important role in the strong smart grid in China. Microgrid has many advantages; however, there are several problems that need to be solved before the large scale application in China.

Lack of national standards and specific policies of microgrid is the priority. There are standards about DER, for example, the IEEE P1547 standard. The standards of DER in China are establishing and amending, but specific standards and national policies of microgrid about the interconnection, design and planning, construction and operation, and manufacturing are still absent.

Second, the microgrid technology is not yet mature. Compare with traditional integrated power generation, the development cost and the operation cost are very high. The microgrid technology needs improving.

Third, the microgrid needs legalizing, and establishing new economic relation with bulk power system. According to the present electricity law of China, the gird-connection microgrid is illegal if it outputs electricity. Meanwhile, the output electricity of private microgrid

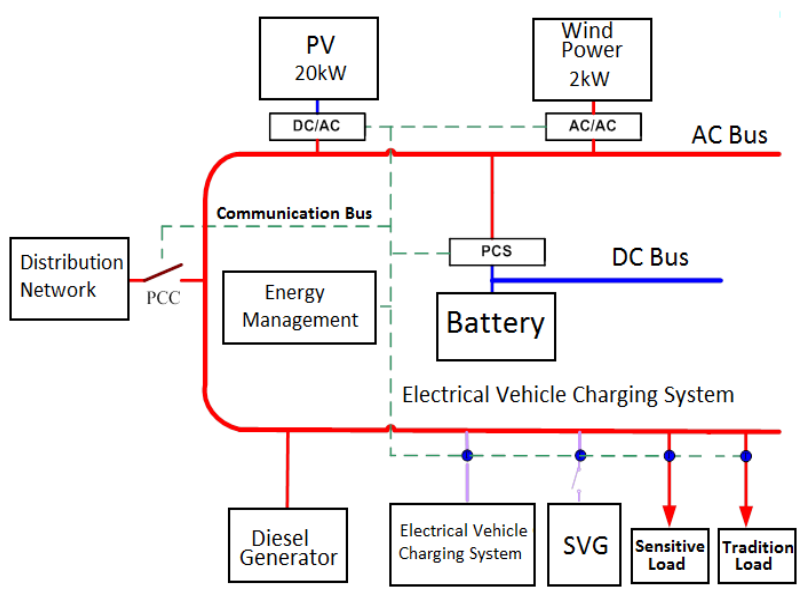

Figure 6. Microgrid in XIHARI. conflicts with the operation of current electric power system. New economic relation should be established to ensure mutual interest.

\section{Conclusions}

The microgrid concept has been proposed and applied for years to solve the interconnection issues of DER to the bulk power system abroad. In China, microgrid develops with the boost of DER (with renewable energy). Though microgrid becomes more and more popular in China, the foundation of microgrid technology is weak, it needs time to realise commercial operation, especially with the support of national policies, laws and regulations. The development of microgrid technology in China is bound to be a long process.

\section{REFERENCES}

[1] B. Lasseter, "Microgrid:Distributed Power Generation," Presented at the 2001 IEEE Power Engineering Society Winter Meeting, Columbus, OH, USA, 2001.

[2] C. Marnay, F. Javier Rubio and A. S. Siddiqui, "Shape of the Microgrid,” In 2001 IEEE Power Engineering Society Winter Meeting, Columbus, OH, United states, 2001, pp. 150-153.

[3] R. H. Lasseter, "MicroGrids," In 2002 IEEE Power Engineering Society Winter Meeting, New York, United states, 2002, pp. 305-308.

[4] R. Lasseter, A. Akhil, C. Marnay, J. Stephens, J. Dagle, R. Guttromson, A. S. Meliopoulous, R. Yinger and J. Eto, "Integration of Distributed Energy Resources," The CERTS Microgrid Concept, Lawrence Berkeley National Laboratory, 2002. doi:10.2172/799644

[5] P. Piagi and R. H. Lasseter, "Autonomous Control of Microgrids,” In 2006 IEEE Power Engineering Society General Meeting, PES, Montreal, QC, Canada, 2006.

[6] D. K. Nichols, J. Stevens, R. H. Lasseter, J. H. Eto and H. T. Vollkommen, "Validation of the CERTS Microgrid Concept the CEC/CERTS Microgrid Testbed," In 2006 IEEE Power Engineering Society General Meeting, PES, Montreal, QC, Canada, 2006.

[7] S. Dai, Y. Zhang and D. K. Zhu, "Distribution Network Planning Method Containing Microgrid,” Automation of Electric Power Systems, Vol. 22, 2010, pp. 41-45.

[8] S. W. Mei and Y. Y. Wang, "Several Basic Problems of Three-level Power Network Planning of Transmission Network-distribution Network-microgrid," Journal of Electric Power Science and Technology, Vol. 4, 2009, pp. 3-11.

[9] J. Shu, X. Y. Zhang,Y. L. Shen and C. H. Wu, "The Algorithm and Application in Power Sources Planning and Designing for Microgrid Based on Distributed Renewable Energy," Control Theory \& Applications, Vol. 5, 2010, pp. 675-680.

[10] M. Wang and M. Ding, "Distribution Network Planning Including Distributed Generation,” Proceedings of Elec- 
tric Power System and Automation, Vol. 6, 2004, pp. 5-8.

[11] C. S. Wang, K. Chen, Y. H. Xie and H. F. Zheng, "Siting and Sizing of Distributed Generation in Distribution Network Expansion Planning," Automation of Electric Power Systems, Vol. 3, 2006, pp. 38-43.

[12] J. Wang, F. R. Li, C. Y. Feng and X. F. Wang, "Real and Reactive Power Pricing for Distribution Networks," Automation of Electric Power Systems, Vol. 15, 2009, pp. 29-32.

[13] C. S. Wang, L. Ma and Guo Li, "Comparison of Operation Characteristics between Two Types of Microturbines in Microgrid,” Journal of Tianjin University, Vol.4, 2009, pp. 316-321.

[14] Y. Wang, Z. X. Lu and Y. Min, "Research and Comparison of DG Interface Simulation Models in a Microgrid," Automation of Electric Power Systems, Vol. 1, 2010, pp. 84-88.

[15] Y. S. Shi, Z. X. Lu, Y. Min and Y. Wang, “Analysis on Microsource Characteristics and Its Influences on Microgrid Load Voltage," Automation of Electric Power Systems, Vol.17, 2010, pp. 68-71.

[16] C. S. Wang, C. X. Xiao and S. X. Wang, "Synthetical Control and Analysis of Microgrid," Automation of Electric Power Systems, Vol. 7, 2008, pp. 98-103.

[17] W. Pei, P. S. Li, H. Y. Li, X. S. Tang, J. Z. Cheng and W. X. Zuo, "Key Technology and Testbed for Microgrid Operation Control," Automation of Electric Power Systems, vol.1, 2010, pp. 94-98.

[18] M. Ding, L. Zhou and R. Bi, "Optimization for Design and Application of Data Acquisition Subsystem in Micro-grid Energy Management System," Journal of Hefei University of Technology(Natural Science), Vol. 12, 2010, pp. 1790-1796.

[19] S. Peng, Y. F. Cao and X. Cai, "Control of Large Scale Battery Energy Storage System Interface to Microgrid," Automation of Electric Power Systems, Vol. 16, 2011, pp. 38-43.

[20] Z. X. Chen, X. D. Liu and J. M. Pan, "Current Control Strategy for Grid-Connected Inverter Based on IDA-PBC," Transactions of China Electrotechnical Society, Vol. 8, 2011, pp. 99-105.

[21] J. J. He and W. L. Wu, "Study on Inverting Control System for Parallel Operation of Distributed Generation," Energy Engineering, Vol. 3, 2007, pp. 1-6.

[22] G. Wei, W. L. Wu, D. Y. Hu and Z. H. Li, "Distributed Generation and Effects of Its Parallel Operation on Power System," High Voltage Engineering, Vol. 1, 2007, pp. 36-40.

[23] B. B. Wu, J. H. Su, J. J. Zhang and D. Zhu, "Control Strategies of Inverter in Microgrid Island Operation," Proceedings of the Chinese Society of Universities for Electric Power System and its Automation, Vol. 1, 2011, pp. 1-5.

[24] F. D. Li and M. Wu, “An Improved Control Strategy of Load Distribution in an Autonomous Microgrid," Proceedings of the CSEE, Vol.13, 2011, pp. 18-25.
[25] X. Zhang and J. J. Liu, “A Novel Power Distribution Strategy for Parallel Inverters in Islanded Mode Microgrid,” Journal of Power Supply, Vol.1, 2011, pp. 38-42.

[26] Q. Yang and J. H. Zhang, "Design of Microgrid Operation Model and Coordinate Protection," Shaanxi Electric Power, Vol. 1, 2011, pp. 1-5.

[27] J. H. Wang, N. L. Tai, K. Song, L. F. Gu and J. Q. Sheng, "Penetration Level Permission of for DG in Distributed Network Considering Relay Protection," Proceedings of the CSEE, Vol.22, 2010, pp. 37-43.

[28] B. Li and Z. Q. Bo, "Design and Research on Protection and Control of Smart Distribution Grid," Proceedings of the CSEE, Vol. S1, 2009, pp. 1-6.

[29] Z. Q. Yang, "The Study on Microgrid Experiment Systems,” Doctor Dissertation, Tianjin University, 2010.

[30] M. Meiqin, D. Ming, S. Jianhui, L. Chang, S. Min and Z. Guorong, "Testbed for Microgrid with Multi-energy Generators," in IEEE Canadian Conference on Electrical and Computer Engineering, Niagara Falls, ON, Canada, 2008, pp. 637-640.

[31] M. Q. Mao, M. Ding, L. C. Zhang, J. H. Su and M. Sun, "Testbed and Information Integration of EMS for a Microgrid with Multi-energy Generation Systems,” Automation of Electric Power Systems, Vol. 1, 2010, pp. 106-111.

[32] B. Wu, J. Liu and F. Zhuo, "The micro-grid Fast Simulation Platform Exploitation Based on PSCAD,” in 26th Annual IEEE Applied Power Electronics Conference and Exposition, APEC 2011, TX, United states, 2011, pp. 1737-1742.

[33] L. Meng, M. J. Yang, X. W. Wang, F. Zhuo and B. Q. Liu, "A Dynamic Reactive Power Compensation Device and Its Control Method for Microgird," China, Patent for invention, 201010522245.2, 2010.

[34] H. P. Guo, L. Meng, X. W. Wang, M. J. Yang, F. Zhuo and Y. J. Zhou, "A Method to Use Virtual Impedance to Improve the Stability of Wireless Connection Between Multiple Inverters in Microgrid,” China, Patent for invention, 201010522213.2, 2010.

[35] S. Zou, W. Pei and Z. Qi, “Common Interface for Interconnection between Distributed Generation and Microgrid,” Automation of Electric Power Systems, Vol. 34, 2010, pp. 91-95.

[36] G. Zhang, X. Tang and Z. Qi, "Research on battery supercapacitor hybrid storage and its application in MicroGrid," in Asia-Pacific Power and Energy Engineering Conference, APPEEC 2010, Chengdu, China, 2010

[37] X. Tang, W. Deng and Z. Qi, "Research on Micro-grid Voltage Stability Control Based on Supercapacitor Energy Storage," in 12th International Conference on Electrical Machines and Systems, ICEMS 2009, Tokyo, Japan, 2009.

[38] L. Guo, D. Xu, C. S. Wang and S. X. Wang, "Energy Optimization and Management of Combined Cooling and Power Distributed Energy Supply System,” Automation of Electric Power Systems, Vol.19, 2009, pp. 96-100. 